\title{
EL FILÓLOGO PEDRO MARTÍNEZ LÓPEZ: UN LIBELISTA LIBERAL IMAGINATIVO
}

\author{
Aline Vauchelle-Haquet \\ CRIAC - Universidad de Rouen
}

Pedro Martínez López nació en 1800 en una familia acaudalada de Villahoz, en Castilla la Vieja. Fue secretario de la Diputación Provincial de Burgos, antes de desempeñar el cargo de secretario de la Junta de Instrucción Pública en Madrid, donde publicó, en 1827, una gramática titulada Principios de la lengua castellana ${ }^{1}$. En marzo de 1830, tuvo que huir de su país, para escapar de las persecuciones del régimen fernandino, que le había condenado a muerte por haber editado, entre 1828 y 1829, seis números de El mundo tal como es, o todos locos, periódico en el que se había atrevido a atacar violentamente al clero y a insultar a la "persona sagrada del Rey", a quien satirizaba mordazmente ${ }^{2}$.

Después de refugiarse en Francia, participó en la desastrosa expedición de Vera de octubre de 1830, en la que los exiliados liberales españoles, deseosos de exportar a su patria la "Gloriosa Revolución de Julio» y convencidos de gozar del apoyo de Luis Felipe, procuraron en vano sublevar a sus compatriotas, bajo la batuta de Francisco Espoz y Mina ${ }^{3}$. En diciembre, don Pedro estuvo confinado en Bergerac, uno de los depósitos en que las autoridades galas agruparon a los refugiados que carecían de recursos económicos. Allí sirvió gratuitamente de intérprete en el Tribunal. Más tarde, en enero de 1832, fue trasladado al depósito de Poitiers, antes de estar autorizado a sentar sus reales en Burdeos, en septiembre del mismo año ${ }^{4}$. Malviviendo de los subsidios otorgados a los proscritos liberales por el Gobierno galo y de alguna que otra clase de castellano que impartía, en diciembre se dirigió al conde de Ofalia, embajador de su país

\footnotetext{
1. Police Générale: Espagnols réfugiés. Dossiers individuels; 1822-1835; Archivo Nacional de Francia (en adelante ANF), dossier F ${ }^{7}$ 12096; PALAU Y DULCET, Antonio, Manual del librero hispanoamericano, $2{ }^{a}$ edición, Barcelona, 1948.

2. ANF: F 12096, n. $^{\circ} 1237$

3. Ibid.

4. Ibid.
} 
en Francia, para beneficiarse de la ley de amnistía que se había promulgado el 20 de octubre, mientras su padre intentaba valerse de su influjo para abogar por él en España. Pero estos esfuerzos resultaron infructuosos pues Martínez López era culpable de un crimen tan odioso que "merecía el más riguroso castigo" ${ }^{5}$. Entonces obtuvo una prórroga de los auxilios que le abonaba la monarquía orleanista ${ }^{6}$ y siguió arremetiendo contra el despotismo desde el exilio.

En agosto de 1832, ya había dado a luz en Burdeos una Representación a Fernando VII, rey de España, panfleto en el que espeta toda una sarta de acusaciones contra el tirano, a quien vaticina, además, un fin trágico ${ }^{7}$. Le reprocha no tener la menor legitimidad, como quiera que arrancó el cetro de manos de su padre con violencia y que, no habiendo renunciado jamás a ese bárbaro principio, luego ha reinado levantando constantemente el puñal sobre sus súbditos, aunque éstos se habían sacrificado por él durante la Guerra de la Independencia ${ }^{8}$. Esa ingratitud del soberano sólo puede compararse con su falta de probidad, su codicia y su lubricidad: ha sumido al pueblo en la desnudez y la miseria, agobiándolo con tributos, para invertir la mayor parte de este dineral en bancos extranjeros y para sustentar el lujo de una muchedumbre de meretrices ${ }^{9}$. En concreto, el Borbón no desea nada más que aniquilar a España y reducirla al estado de desierto, con el fin de gobernar sin trabas un país poblado en exclusiva por frailes y langostas, unos animales tan devastadores unos como otros ${ }^{10}$.

Pero, a juicio de Martínez López, ha tocado ya la hora de rendir cuentas. España se niega a seguir sometida al capricho más brutal y requiere leyes. España quiere libertad, por cuanto sin ella no puede prosperar. España quiere la igualdad ante la ley, sin la cual el pobre siempre es el esclavo del rico ${ }^{11}$. España, en fin, quiere acabar con las exorbitantes prerrogativas que el despotismo ha concedido al clero ${ }^{12}$ :

"Es un escándalo que este cuerpo de holgazanes posea, sin otro trabajo que rezar, una tercera parte del producto total del territorio... Es preciso que (los eclesiásticos) se conformen con la doctrina de Jesucristo; sean sus apóstoles en la tierra y, si sus trabajos no son bastante recompensados por los hombres, Dios está en el cielo que les pagará centuplicado... He aquí el remedio y el consuelo que ellos aplican a nuestros reveses» ${ }^{13}$.

5. Ibid.

6. Ibid.

7. MARTínez LÓPEZ, Pedro, Representación a Fernando VII, rey de España, Burdeos, Imprenta de Carlos Lawalle Sobrino, 1832, 68 p., Signatura Biblioteca Nacional de Francia (en adelante BNF): Oc-1018.

8. Ibid., ¿Sobre qué títulos apoya V. M. el derecho de su reinado? ¿Será sobre la violencia con que V. M. celebró su inauguración, arrancando el cetro de la mano paternal y amenazando los días del mismo que le dio el ser? En tal caso, no es de extrañar que V. M. fiel a este bárbayo principio, haya seguido con el puñal levantado sobre el pueblo español, Ibid, pp. 8-9.

9. Ibid., pp. 14 \& 19-20.

10. Ibid, pp. 45-46.

11. Ibid, p. 24.

12. Ibid., p. 25.

13. Ibid., pp. 26-27. 
Empero, por más que nunca desista de su anticlericalismo virulento, propio de los liberales progresistas, don Pedro aparece como un creyente sincero, incluso en cierta medida, como un heredero de los católicos ilustrados dieciochescos. Efectivamente, si bien exhorta a sus compatriotas a que se libren de "ese fango pútrido y pestilente que cubren tantos miles de sotanas», al mismo tiempo lamenta con mucha amargura que la palabra de Dios, que debe ser persuasiva y dulce, «llena de verdad y de clemencia, único destino que le dio el Salvador del mundo", haya sido transformada por esos anticristos que son los sacerdotes en una espada de doble filo, "haciendo servir el uno contra la razón de que Dios dotó al hombre, y el otro contra el Evangelio que recomienda la fratemidad, la igualdad $y$ la libertad ${ }^{14}$. Por ende, a ojos de nuestro autor, la fe verdadera es plenamente compatible con la fórmula trina de la Revolución francesa, aunque la enuncie invirtiendo los términos y anteponiendo la fraternidad, por ser el principio primordial que promueve el Nuevo Testamento. De ahí que se empeñe en convencer a los españoles de que los liberales, que quieren regenerar su patria, no tienen ninguna intención de atentar a la religión, que todos veneran. Aducir el contrario es mera difamación, no es más que una calumnia propalada por los frailes y el rey, quienes son los enemigos más encarnizados del pueblo y los únicos responsables de su ruina ${ }^{15}$.

En buena lógica, pues, Martínez López alienta a sus conciudadanos a que se insurreccionen contra la injusticia y el terror, a que reconquisten sus derechos y recuperen las riquezas usurpadas por unos hombres cuyo charlatanismo ha eclipsado su razón natural ${ }^{16}$. Los españoles deben unirse sin demora para arrebatar el cetro de manos de ese monarca sanguinario y criminal y para eliminar todo tipo de opresión ${ }^{17}$. Recurriendo a los manes de los legendarios Empecinado, Riego y Torrijos, estos héroes del panteón liberal, nuestro libelista incita también a los soldados a sublevarse, ya que pertenecen al pueblo y que sufren las mismas vejaciones que éste. Los puestos de mando son para los nobles, mientras que ellos sólo conocen los calabozos y la muerte precedida por un tétrico redoble de tambor. ¡Qué renieguen del infame estandarte del rey "patricida" y que restablezcan las leyes venerables de que el pueblo se dotó entre los cañonazos napoleónicos! ${ }^{18}$

Desde luego, los ímpetus revolucionarios de don Pedro no encontraron eco en España a la sazón. No obstante, por lo menos tuvo pronto la satisfacción de saber que el Borbón había exhalado el último suspiro, lo que le inspiró la publicación, en diciembre de 1833, de una obrita titulada La España en 1833,

\footnotetext{
14. Ibid., pp. 56-57.

15. Ibid., p. 57.

16. Ibid., pp. $57-58$.

17. Ibid., pp. 63-64.

18. "Acordaos que pertenecéis al pueblo y que las vejaciones que pesan sobre él os alcanzan... Los mandos son para los hijos de los marqueses y de los palaciegos, para vosotros los calabozos y la muerte precedida del eco lúgubre de un tambor.. Abjurad el odioso estandarte que enarbola ese rey patricida y plantifiquemos sobre la Iberia el trono de las leyes venerandas que el pueblo sancionó entre el estruendo del cañón imperials, lbid., pp. 66-67.
} 
al expirar Fernando VII... ${ }^{19}$ En realidad, se trata de la traducción por Martínez López de distintos artículos que dio a luz Henri Fonfrède en su diario Le Mémorial bordelais. Este publicista, fervoroso partidario de Luis Felipe, invitaba a la regente María Cristina a deshacerse del influjo del clero y a destruir su poder económico, a amnistiar de una vez a todos los liberales sin excepción y a sellar con ellos una alianza sólida y sincera, para instaurar en España un Gobierno de "justo medio", inspirado en el del rey ciudadano, condición, a su parecer, sine qua non para triunfar sobre el carlismo.

Luego, don Pedro añade motu propio un colofón, en el que bosqueja de su país un cuadro tan desconsolador como halagüeño: un auténtico Dos de Mayo, exclama, puesto que España es víctima de la guerra y de la tiranía, pero también porque está demostrando al resto del mundo lo que son el honor nacional, el amor a la patria y el heró́smo ${ }^{20}$. Esta España no admitirá el absolutismo como herencia de Fernando VII ${ }^{21}$. Y, en contraposición con Fonfrède, quien juzgaba la Constitución de 1812 como excesivamente democrática, Martínez López propugna la adopción de una ley fundamental, cuyas líneas generales y cuyo espíritu recuerdan el Código gaditano:

"El trono es sagrado e inviolable. Bajo su égida, con la protección de la ley y la salvaguardia de la fuerza armada, las personas de los Españoles, sus propiedades y libertad están garantidas (sic) y aseguradas. La responsabilidad será rigurosamente exigible. Y para remedio seguro en todo, la Nación, por sus representantes en Cortes, manifestará sus votos, expondrá sus necesidades, denunciará los abusos, clamará contra las injusticias y propondrá lo más conveniente según las circunstancias de los tiempos» ${ }^{22}$.

Hasta entonces, nuestro autor se distingue bien poco de la mayoría de los liberales que tomaron la pluma para vilipendiar el despotismo y para exigir el restablecimiento de la mítica Constitución de Cádiz que, a su juicio, era el único texto capaz de garantizar la instauración de un régimen liberal que se preciara de ser auténticamente democrático ${ }^{23}$. Pero, a continuación, don Pedro cambió de método, renunció al anatema y a las imprecaciones, se valió de su imaginación y optó por el escarnio para atacar a sus enemigos políticos. Así

19. MARTÍNEz López, Pedro, España en 1833, al expirar Fernando VII, con la traducción de los interesantisimos artículos publicados en El Memorial Bordelés por el ilustre girondino $\mathrm{Mr}$. Henri Fonfrède, sobre las causas de los males que ha sufrido y los medios de hacerlos desaparecer de una vez. Dedicada a su patria por Don-, Burdeos, Imprenta de Pedro Lavigne Joven, 1833, 70 p., Signatura BNF: Oc-1068.

20. Ibid., p. 64 .

21. Ibid., p. 67.

22. Ibid, pp. 69-70.

23. VAUCHELle, Aline, "El Dardo, périodique brûlot lancé par le colonel libéral Nicolás Santiago y Rotalde, 1831», El Argonauta español, n. 2 (2005), http:argonauta.imageson.org/document.48 html; "España y América en progreso, una publicación republicana editada en París, 1834-1835", en prensa. 
publicó en 1834, todavía en la capital girondina, Una noche en el infierno, vista entre sueños, obra que se reeditó en $1836^{24}$.

Una noche en el infierno... fue escrita justo después de la muerte de Fernando VII, cuando la Regente había conservado al último Gobierno nombrado por su real esposo, el de Francisco Cea Bermúdez. Por mucho que diera algunas pruebas de apertura a los liberales, dicho gabinete -en el que el antiguo afrancesado Javier de Burgos, desempeñaba un papel preeminente a la cabeza del recién creado Ministerio de Fomento-, mantuvo incólume todo el sistema de la monarquía absoluta, con la esperanza de ganarse a los carlistas.

Por consiguiente, Martínez López cubre de oprobio a ese Gobierno de Cea que, a sus ojos, no se diferencia en nada del régimen arbitrario del Borbón. En cuanto al finado monarca, sigue vituperándole post mortem, culpándole de haber enmarañado a sabiendas el problema de su sucesión, para desatar la salvaje guerra civil que está asolando a España. Tampoco se priva del gusto de fustigar a los religiosos quienes, para mantener su dominio sobre el poder y la sociedad, atizan el odio entre los españoles y cuyos conventos se han convertido en guaridas para los conspiradores carlistas.

Pero, como literato que es, don Pedro no se contenta con redactar un nuevo libelo. Escribe una fábula en que pretende haber pasado, entre sueños, una noche en el infierno, donde ha presenciado el juicio de varias personalidades políticas españolas. Por cierto, el Borbón es el principal encausado en el pleito y los realistas, representados por Cea, su líder, también están en el banquillo de los acusados. Del mismo modo, los afrancesados tienen que rendir cuentas: se les culpa de traición y Javier de Burgos encarna de por sí la quintaesencia de todas sus bajezas, por lo advenedizo, venal y corrupto que se le presenta. También asisten a esta vista El Empecinado, Riego y Torrijos, en calidad de testigos.

Martínez López pinta un Plutón absolutamente terrorífico, como también lo son los incontables demonios que constituyen su tribunal infernal. Sin embargo, a diferencia de los reos, son capaces de mostrarse benévolos hacia los inocentes. Más aún, por muy diabólicos que sean, abrazan la justa causa, por cuanto tomarán partido por el liberalismo, aunque esta postura les venga dictada por la defensa de sus intereses propios. El símbolo es evidente, Fernando VII $y$ todos los secuaces del absolutismo forman una maldita ralea infinitamente más maléfica que las potencias demoníacas que reinan en la gehena.

A guisa de preámbulo, el dios de los Infiernos desahoga su ira contra España porque no le facilita el número de almas con el que podría contar, tomando en cuenta el fanatismo y la falta de virtud que imperan en ese país. El motivo es que se ha vuelto casi desértico, bajo el yugo del despotismo ${ }^{25}$. En cambio, si se instaurara un régimen liberal, la población, ya libre de todas las trabas impuestas por el clero y de todas las coacciones políticas, incrementaría y se reprodu-

24. Martínez López, Pedro, Una noche en el infierno, vista entre sueños, Burdeos, Imprenta de Peletingeas, 1834, 71 p., Signatura BNF: 8-Yth-65657; Ibid., Burdeos, Imprenta de la $S^{a} V^{a}$ Laplace y Beaume, 1836, 212 p., Signatura BNF: Y2- 49468.

25. Ibid., pp. 27-28. 
ciría maravillosamente, lo que proporcionaría a la Mansión de los réprobos por lo menos una mitad de prosélitos más ${ }^{26}$.

A continuación, empiezan los interrogatorios de los procesados, y a tal señor tal honor, Fernando es el primero en comparecer. Se apresura a afirmar su gran lealtad y su total adhesión al Reino de las Tinieblas. Todos mis hechos y milagros lo testimonian, según se glorifica: desde mi entronización, no he hecho más que asesinar, proscribir, perseguir y aniquilar a los españoles. Cuando estaba obligado por las circunstancias, recurría al engaño y a la doblez, prometiendo instituciones y reformas a mis vasallos, pero luego que me veía con fuerza para ponerles el pie encima, caía sobre ellos y les mandaba a la horca. He asesinado a liberales, realistas, carlistas, afrancesados. Y todo ello para tener el menor número posible de súbditos, pues cuanto menos poblado está un país, más fácilmente se le esclaviza ${ }^{27}$.

"Tenga presente, Vuestra Majestad Satánica, que un país libre es un país en guerra abierta contra el Infierno: el filósofo, el poeta, el publicista, el romancero, y en fin todos los mejores ingenios trabajan noche y dia para transmitir sus doctrinas a la sociedad en que viven; los hombres empiezan poco a poco a pensar y a conocer la dignidad de su ser, se hacen vituosos insensiblemente, los vicios y los crimenes se disminuyen o desaparecen enteramente y por más sutiles $y$ diligentes que anden los demonios, nunca pueden prosperar ni conquistar las almas» ${ }^{28}$.

En contraste, España, en el estado a que la han rebajado mis atrocidades es una mina que V. M. puede explotar como se le antoje:

«Supongamos que V. M. necesite un día veinte mil familias españolas, con sólo dar un leve aviso a los frailes y a los curas, verá V. M. llenado el contingente. A la voz de RELIGIÓN, los españoles se degüellan con un placer, con un entusiasmo y con una docilidad sin ejemplo en los anales" ${ }^{29}$.

Pero, para que este argumento conserve su fuerza persuasiva, es menester que toda la riqueza permanezca en manos del clero y que el pueblo siga viviendo en la ignorancia y la miseria ${ }^{30}$.

Cuando le toca declarar a Cea Bermúdez, hace alarde de un cinismo que no le va a la zaga al de su antiguo amo. Como réplica a una acusación del monarca, rechaza haber introducido progresos y asegura que no contempla modificar de modo alguno el sistema destructor de Fernando. Nuestra alianza con los liberales se deriva únicamente de las circunstancias, expone a Plutón:

«Si logramos consolidar el gobierno llamado de Isabel II, deshecha la facción..., volveremos a nuestras antiguas mañas, destruiremos a troche y moche a los constitucionales, y caso necesario pondremos en Ceuta o en la horca a los que nos sirvan de estorbo: ${ }^{31}$.

26. Ibid., p. 28.

27. Ibid., p. 32.

28. Ibid., pp. 33-34.

29. Itid., pp. 34-35.

30. Ibid., p. 35 .

31. Ibid., pp. 47-48. 
Como dice Fernando con razón, España no debe ser libre:

"Trabajen y remen los españoles para que nosotros derrochemos el fruto de su sudor... Así pues, Majestad Infernal, os pido frailes en abundancia y yo y mis compañeros al frente de los negocios”32.

Exasperado por tanta impudencia, Torrijos suplica entonces al señor de los Infiernos que saque a España del estado vil y lastimoso a que la ha reducido el despotismo y que haga lo necesario para que el pueblo español obtenga por fin las instituciones que se merece ${ }^{33}$. Con este propósito, sugiere mandar a España algunas legiones de los diablos más diestros y avispados para fomentar una revolución general que derroque al ministerio, que purgue los conventos de la pestilente canalla que los habita y que reparta los bienes nacionales entre los ciudadanos más pobres ${ }^{34}$.

En esto, ha llegado la hora de la requisitoria que corre a cargo del demonio Asmodeo. El fiscal empieza advirtiendo a Plutón que el Reino de las Tinieblas cometió un error garrafal al colocar a Fernando en el trono. Se queja de que, si bien nunca se derramó tanta sangre, el Infierno no sacó ningún provecho dado que sólo se inmoló a los buenos, a aquellos que luchaban por la felicidad de sus conciudadanos y de las generaciones venideras. Ahora bien, a éstos se los lleva el Olimpo ${ }^{35}$. Y hoy en día la guerra civil que está devastando el país tampoco es rentable, según opina Asmodeo:

«Qué adelantamos con que los españoles se degüellen entre si? Examine V. M. los cuerpos de un campo de batalla y hallará lo que nuestros diablos hallan, es decir solados que se baten contra la facción y facciosos que se baten contra soldados; rara vez un FRAILE, un CURA, un CABECILLA, un hombre de provecho en fin, y sobre el cual pudiéramos tener derechos incontestables... Tenemos en España dos o tres escuadrones de demonios encargados de recoger los muertos de uno y otro campo y, a pesar de que diariamente hay más vítimas, la mayor parte de nuestros delegados aún no han logrado apoderarse de un solo individuo. Por todas partes se encuentran con los alguaciles del Olimpo que recogen a éstos porque pertenecian a las tropas de Isabel, a aquellos porque, aunque facciosos y conducidos por jefes de nuestra elección, se los considera seducidos, engañados y victimas inocentes de la perfidia, de la mentira de sus instigadores» ${ }^{36}$.

Por lo tanto, si Plutón deja que se prolongue esa guerra, La Mansión de los Réprobos perderá su crédito y su potencia. Del mismo modo, continuará la decadencia si Su Majestad Demoníaca consiente que don Carlos se adueñe de la corona. Como digno hermano de su hermano, ensangrentará al país, encenderá las hogueras de la Inquisición para sacrificar doncellas y mujeres recatadas, así como hombres honrados y virtuosos, en una palabra, unas personas que se lle-

32. Ibid., pp. 49-50

33. Ibid., p. 53.

34. Ibid., p. 55.

35. Ibid., pp. 85-86.

36. Ibid., pp. 86-88. 
vará en seguida el Olimpo, cuyo imperio seguirá extendiéndose, en detrimento de los Infiemos ${ }^{37}$.

Con vistas a compensar las pérdidas que han experimentado en los últimos 25 años, el fiscal juzga conveniente que:

«V.M. trastorne el actual estado de cosas en España, haciendo que los españoles pasen de un extremo a otro. Al atroz despotismo que Fernando fundó, y que, algo paliado, los ministros actuales se esfuerzan en perpetuar, debe suceder una libertad, segun ya se nos ha hecho necesaria. Esta libertad, ... protectora de las ciencias, de las artes y de la prosperidad general, no puede menos de dar un impulso veloz a los pueblos, acrecentando de un modo prodigioso la especie humana e ilustrándola en todos los ramos, que es una de las condiciones más esenciales al engrandecimiento del Infierno. La España tiene, más que ninguna otra nación, una necesidad urgente de esta libertad, para que destierre la ignorancia crasa que la consume. ¿Qué quiere V. M. hacer con los españoles, si no se los instruye bajo otros principios y bajo otra escuela diferenter ${ }^{38}$.

Efectivamente, para ser diablo, es menester saber mucho, ser travieso y tener talentos a toda prueba. De momento, los españoles ni siquiera son bastante astutos para servir de porteros o de barrenderos del Infierno. Por eso, Asmodeo ruega a Plutón que provoque la reunión de las Cortes, que exhorte al pueblo a vengarse de todos los ultrajes que ha sufrido y que le señale los responsables de sus males. Entonces, triunfará el Reino de las Tinieblas, pues llegarán al menos unos 200.000 frailes, un sinnúmero de curas y de canónigos repantigados, varios ministros y consejeros, o sea todos aquellos que se han alistado en nuestras banderas desde hace mucho tiempo ya ${ }^{39}$. El Infierno sacará entonces inmensos bienes:

"Nuestras FURIAS, apoderándose de esos ejércitos de FRAILES y de esos ministros del despotismo, nos adobarian carne para muchos meses... El plato más exquisito, y el que más preferiría V. M. sería una anca, una chuleta de FRAILE..., el más fresco que la holganza y la molicie produjeron jamás... Y ¡cuánta grasa no nos darian estos hombres, Señorl... Grasa para refrescar los resortes y goznes de nuestras infernales máquinas...; grasa amasada y petrificada entre la pereza, el placer y el descanson ${ }^{40}$.

En el momento de fallar las sentencias, recogiendo los mismísimos términos empleados por el Borbón cuando arruinó la obra de los liberales en 1814 y en 1823, Plutón declara nulo, de ningún valor ni efecto el ominoso sistema de Fernando VII y decreta el mando a España de 15 legiones infernales encargadas de desatar la revolución ${ }^{41}$. Y en seguida, miles de íncubos se abalanzan sobre el tirano, que está condenado a tormento perpetuo y que estará sometido a todas las torturas que los avances científicos y técnicos permitan inventar a los demonios $^{42}$. En cambio, Riego, Torrijos y El Empecinado estarán acompañados

37. Ibid., pp. 88-89.

38. Ibid., p. 90.

39. Ibid., pp. 91-92.

40. Ibid., pp. 93-94.

41. Ibid., pp. 133-135.

42. Ibid., pp. 106, 137-138. 
con todos los honores al Olimpo, donde ya residen y están colmados de bendiciones por sus altas hazañas. Además, tendrán la dicha de comprobar que no se han sacrificado en vano, porque España estará regenerada ${ }^{43}$. En lo que atañe a Cea Bermúdez y a Javier de Burgos, volverán a sus cargos respectivos, para que estalle cuanto antes la revolución que están promoviendo con sus maquinaciones criminales ${ }^{44}$.

De pronto, Martínez López interrumpe su cuento socarrón, pues, al despertar, se entera de que las columnas que Plutón envió a España han actuado con una habilidad verdaderamente diabólica: Cea acaba de ser destituido, las Cortes van a reunirse y la Regente ha entregado las riendas del poder a Martínez de la Rosa ${ }^{45}$.

El fin del absolutismo suponía, por cierto, una victoria que presagiaba un cambio decisivo para España. No obstante, don Pedro no podía quedar satisfecho con el liberalismo tibio instaurado por el nuevo gabinete, con esta política de «justo medio» que tenía por objeto seducir a los absolutistas «templados». Por ende, no soltó prenda y, en 1835, publicó Las Brujas en Zugarramurdi, otro relato en el que zahería el conservadurismo del régimen instituido por el Estatuto Real ${ }^{46}$.

Cultivando resueltamente su inclinación hacia las paradojas y manifestando una marcada afición a las criaturas satánicas, esta vez nuestro autor encomienda la defensa de la justa causa a unas brujas ${ }^{47}$. O quizá llegase a pensar que el liberalismo, tal como él lo concebía, sólo podría triunfar en España por arte de magia.

Después de enfurecerse con la creación de la cámara alta y de exigir la reposición del sufragio universal ${ }^{48}$, Martínez López es llevado por su gato, repentinamente convertido en demonio, a un anexo del Infierno. Se trata de la cueva de Zugarramurdi, este pueblo de Navarra, rodeado de grutas, y en el que, según las leyendas, todas las hechiceras de la comarca solían celebrar bacanales y aquelarres, lo que desencadenó una férrea represión del Santo Oficio, a principios del siglo XVII. Al narrador le acogen la tía Rosenda, la bruja en jefe, y unas cien comadres suyas. Rosenda, quien le sirve de portavoz a don Pedro, acusa al Gobierno de Martínez de la Rosa, del que se esperaba la regeneración de España, de precipitarla, al revés, hacia la ruina, por no hacer nada para atajar la contienda civil. Por consiguiente sólo una revolución general podrá acabar con esa guerra ${ }^{49}$. De hecho, afirma la maga:

43. Ibid., pp. $107 \& 139$.

44. Ibid., pp. 139-140.

45. Ibid., pp. 150-151.

46. VAUCHELIE, Aline, Les Ouvrages en langue espagnole publiés en France au temps de la Première Guerre carliste..., p. 125.

47. MARTÍnEZ LÓPEZ, Pedro, Las brujas en Zugarramurdi, Burdeos, Imprenta de Laplace y Beaume, 1835,167 p., Signatura BNF: Oc-1471.

48. Ibid., pp. 18-19.

49. Ibid., p. 47. 
"No son las armas las que restablecerán la paz, no: el germen de destrucción, de sangre y de discordia no ha de buscarse entre las hordas de Zumalacárregui; jestá en los conventos, está en las iglesias, está en las catedrales! Se elabora y se fortifica en fin en el santuario que debiera solamente servir de asilo $y$ de sustento a la paz y a la clemencia... El clero está corrompido y pútrido; su dolencia es sumamente contagiosa, ningún remedio es capaz ya de mejorar su condición; por consiguiente, o el pueblo español va a ser víctima de aquel miembro, o forzoso es, si salvarse quiere, amputar sin tardanza la parte maleada y contagiosa. ¿Se piensa en este remedio? Al contrario, el gobierno quiere conservar a toda costa este miembro roedor y corrosivo y aún le llama a deliberar en los negocios públicos, para que más a salvo pueda extender el mortifero veneno que en su seno alimenta y vivificas ${ }^{50}$.

Los gobernantes moderados incluso tienen el descaro de alegar que se perdió la libertad en 1823 por culpa de los abusos de los exaltados, lo que es falso. En rigor, la libertad murió debido a la excesiva indulgencia y generosidad de los liberales, que tenían una fe ciega en la sagrada causa que propugnaban. $Y$ en la actualidad, la libertad aún está amenazada, como quiera que los ministros pretenden operar una reforma lenta y progresiva, mientras que el pueblo reclama para salvarse bayonetas y medidas enérgicas ${ }^{51}$. Juzgando pues que España queda muy a la zaga de un pueblo que los europeos consideran como idiota y salvaje, la tía Rosenda sugiere inspirarse en una legislación que atribuye supuestamente a Turquía. Según el Código de este país:

"Todos los musulmanes están bajo el imperio de las leyes, incluso el Sultán, el cual incurre en la pena de muerte si alguna de ellas viola; en la destitución si atentase contra ellas sin que el atentado produzca efecto ni resultado alguno.

Las leyes del imperio no reconocen nobleza ni personas privilegiadas.

Todos los súbditos son iguales ante la ley. Ninguno puede ser desposeido de sus bienes, ni condenado a pena alguna, sin que lo contrario en juicio se determine; todos son pecheros $y$ todos optan a los empleos civiles y militares.

El poder ejecutivo es la única y sola prerrogativa del Sultán: él no puede declarar la guerra, ni hacer la paz, ni pronunciar en ningín negocio administrativo o de alto interés del estado; esto toca al Diván.

El Sultán no puede jamás presidir su Diván, ni tener voto en él, ${ }^{52}$.

Espantado por tanto radicalismo, Minos, el juez de los Infiernos, quien habla en nombre de los moderados, replica que si los progresistas llegaran al poder y pusieran en marcha semejante programa, gobernarían mediante el terror, multiplicando los cadalsos y España sería presa de una horrorosa anarquía ${ }^{53}$-lo que demuestra que el espectro de la Revolución francesa y del jacobinismo todavía se podía utilizar como espantajo-. Pero, a ojos de Rosenda, basta ya de compromisos y acomodos, la política de Martínez de la Rosa no es más que despotismo ilustrado y su ministerio se revela tan nefasto como el de Cea Bermúdez. En contra de lo que afirma el gabinete, que se propone remedar las instituciones

50. Ibid., pp. 48-49.

51. Ibid., p. 53.

52. Ibid., pp. 64-65.

53. Ibid., p. 66. 
francesas, es imposible el «justo medio» en España: o ganará la Inquisición con los carlistas, o triunfarán la justicia y la igualdad con el verdadero partido de la libertad ${ }^{54}$. Y, para acelerar el proceso, Rosenda y sus hermanas fomentan, en los jardines de La Granja, un tumulto ante el cual el Gobierno no tarda en darse por vencido. Tras su pronta victoria, son entonces las brujas las que dictan las nuevas leyes que, en adelante, regirán el país:

«La ley protege la libertad puiblica e individual contra la opresión de los que gobieman.

La igualdad es la ley fundamental de la sociedad.

La vida del hombre es sagrada.

El Pueblo es el soberano y en él exclusivamente reside el poder legislativo.

Todo ciudadano tiene derecho a escribir y publicar sus opiniones sin restricción.

Queda establecida y decretada la libertad de cultos; el Estado atenderá a la subsistencia de los ministros de todos ellos.

Todas las órdenes religiosas son abolidas; los conventos y las propiedades que a éstos pertenecian son bienes nacionales.

Las leyes determinarán el número y las atribuciones de los ministros, las que quedar deban en el jefe del Estado, las obligaciones y responsabilidad de los funcionarios públicos, y todo cuanto necesario sea para perfeccionar la administración en lo militar, civil y religioso.

Se declara nulo todo to hecho desde el 30 de septiembre de 1823 hasta el dian ${ }^{55}$.

En este sentido, Martínez López estimulaba con la pluma el movimiento revolucionario que había estallado en julio de 1835 y entre cuyos motivos principales, amén del peligro carlista y de la inquina popular hacia los religiosos, destacaba la movilización en pro de la Constitución de Cádiz ${ }^{56}$. Así anticipaba don Pedro, mediante la ficción, el motín de los sargentos de la Guardia Real que se verificó en La Granja, en agosto de 1836 y que desembocó en la restauración de dicho texto ilustre.

Sin embargo, pese a que los principios que postulaba a través de la tía Rosenda y de sus compinches eran mucho más drásticos que los del Código gaditano, señaladamente en materia religiosa, y aunque sus posturas se habían radicalizado desde la publicación de La España en 1833, al expirar Fernando VII, Martínez López no evolucionó hacia el republicanismo, a diferencia de su amigo el general Pedro Méndez de Vigo, que era un ardoroso partidario de esta doctrina ${ }^{57}$. Hasta es posible que acabase contentándose con la Constitución de 1837, que fue el fruto de un compromiso entre moderados y progresistas, porque dejó de escribir panfletos y parábolas políticas. Empero, no abandonó el combate contra el carlismo y sirvió la causa isabelina como agente secreto ${ }^{58}$.

54. Ibid., pp. 125-128.

55. Ibid., pp. 133-134.

56. MOLINER, Antonio, Revolución burguesa y movimiento juntero en España, Lleida, Editorial Milenio, 1997, p. 168.

57. VAUChELle, Aline, "España y América en progreso, una publicación republicana editada en París, 1834-1835", en prensa.

58. "Cartas escritas por Martínez López a Aviraneta en 1840", en Cuademos de historia, tomo IV: Estudios sobre la España liberal, 1808-1848, Madrid, Instituto Jerónimo Zurita, C.S.I.C., 1973, pp. $375-380$. 
Luego, durante los muchos años en que residió en Francia, don Pedro volvió a dedicarse a sus trabajos de erudición. Publicó en París en 1840 unos Principios de la lengua castellana, o prueba contra todos los que asienta Don Vicente Salvá en su gramática ${ }^{59}$, en el que, conforme reza el título, polemizaba con el afamado librero y filólogo Vicente Salvá ${ }^{60}$. Al año siguiente, en colaboración con François Maurel, elaboró un Dictionnaire français-espagnol et espagnol-français, del que salieron a la luz nada menos de cinco ediciones hasta $1866^{61}$. Don Pedro asimismo compuso en 1844 un Dictionnaire français-espagnol et espagnol-français, rédigé d'après la dernière édition du Dictionnaire de l'Académie Française et celle du Dictionnaire de l'Académie Espagnole, que se reimprimió cuatro veces en París hasta $1866^{62}$. En 1847 y todavía en la capital gala, publicó una Gramática de la lengua castellana, que conoció tres reediciones hasta $1856^{63}$. Y, entre sus numerosos trabajos de lingüista -de los que sólo mencionamos los principales-, aún cabe citar un Valbuena reformado. Diccionario latino-español que lleva además un vocabulario español-latino, que se puso en prensa cuatro veces hasta $1865^{64}$. Por lo demás, siendo un espíritu ecléctico, Martínez López poseía amplios conocimientos en materia de agronomía y redactó en 1861 un manual titulado El granero de los labradores, en el que exponía el funcionamiento de distintas máquinas de su invención, destinadas a facilitar y mejorar la siembra y la cosecha de los cereales ${ }^{65}$.

59. VAUCHELLE, Aline, Les Ouvrages..., p. 187.

60. ReIG SALVÁ, Carlota, Vicente Salvá, un valenciano de prestigio internacional, Valencia, Institución Alfonso el Magnánimo, 1972, 344 p.; VAUCHELlE, Aline, "Vicente Salvá, un filológo, librero y editor español en París (1830-1849)", en Exiliados. La emigración cultural valenciana (siglos XVI-XX), Generalitat Valenciana, Consellería de Cultura, 1995, pp. 99-112.

61. Catalogue des ouvrages imprimés de la Bibliothèque Nationale de France.

62. Ibid.

63. Ibid.

64. Ibid.

65. MARTínez López, Pedro, El granero de los labradores, París, Imprenta de Dubuisson y Cía, 1861 , 24 p., Signatura BNF: SP 6213. 